\title{
Ecological Aspects of the Predominant Species of Phlebotominae Sand Flies (Diptera: Psychodidae) in Hamadan, Iran
}

\author{
Somayeh Rafatbakhsh-Iran, ${ }^{1}$ Aref Salehzadeh,,${ }^{1,}$ Mansour Nazari, ${ }^{1}$ Amir Hosein Zahirnia, ${ }^{1}$ Behroz \\ Davari, ${ }^{1}$ Milad Latifi, ${ }^{1}$ and Parisa Chamanpara ${ }^{2}$ \\ ${ }^{1}$ Department of Medical Entomology and Vector Control, Faculty of Medicine, Hamadan University of Medical Sciences, Hamadan, IR Iran \\ ${ }^{2}$ Department of Statistics, Faculty of Health, Hamadan University of Medical Sciences, Hamadan, IR Iran \\ "Corresponding author: Aref Salehzadeh, Department of Medical Entomology and Vector Control, Faculty of Medicine, Hamadan University of Medical Sciences, Hamadan, IR \\ Iran. E-mail: a_salehzadeh@yahoo.com
}

Received 2014 February 16; Accepted 2014 March 12.

\begin{abstract}
Background: Leishmaniases are important diseases in many parts of the world, which are transmitted by bites of sand flies. Objectives: This study aimed at investigating some ecological aspects of sand flies in Hamadan.

Materials and Methods: In this descriptive cross-sectional study, sand flies were collected weekly by sticky traps.

Results: For this study, 3305 sand flies were collected and identified during 2013. Sand flies active season began from May till October in Hamadan. The greatest activity occurring between 08:00 pm till 12:00 pm.

Conclusions: In order to avoid the possible transmission of diseases and reduction of harassments of sand flies, especially in the period of greatest activity, personal protection is recommended.
\end{abstract}

Keywords: Ecology, Phlebotminae Sand Flies, Leishmaniasis, Iran

\section{Background}

Phlebotminae sand flies are considerable public health problem because of their ability to transmit several pathogenic organisms to humans and other animals [1]. During past 30 years, important advances have been made in understanding the biology and the ecology of Phlebotminae sand flies and their importance to transmission of bartonellosis, phleboviruses, vesiculoviruses and specially leishmaniasis [2]. Two forms of leishmaniases in Iran are VL (visceral leishmaniasis) and CL (cutaneous leishmaniasis) [3]. CL is the most prevalent leishmaniasis in the world [4]. CL is endemic in 88 countries in Africa, Asia, Europe, North and South America, 90\% of all cases take place in six countries that including Afghanistan, Brazil, Iran, Peru, Saudi Arabia and Syria [5].

VL is public health problem in Iran and some other countries [3]. Also sand flies cause annoyance by their painful bites, which may produce allergic reactions [6]. Of approximately 900 sand fly species in the world, about 50 have been concerned as vectors of leishmaniasis [7].

In the old world, Phlebotomus papatasi and Phlebotomus sergenti are recognized as the main vector of CL [3]. Species of Sergentomyia feed predominantly on reptiles, but the Phlebotomus feed mainly on mammals [8].

The ecological aspects of the leishmaniasis vectors have not been examined in Hamadan district yet. Without correct identification of sand flies species and their ecological aspects, prevention and control of leishmaniasis is difficult to achieve.

\section{Objectives}

The objectives of the present study were to determine the sand flies species population density, seasonal activities and hourly pattern of activities.

\section{Materials and Methods}

This is a descriptive cross-sectional study. The city of Hamadan is the center of province ( $\left.34^{\circ} 52^{\prime} \mathrm{N}, 48^{\circ} 35^{\prime} \mathrm{E}\right)$ with an area of $4,084 \mathrm{~km}^{2}$. It is located at an altitude of 1,820 meters above sea level. The climate is basically cold and semidry. The maximum registered temperature is $38^{\circ} \mathrm{C}$ and minimum $-25^{\circ} \mathrm{C}$ in July and February, respectively. The minimum mean monthly relative humidity is $43.33 \%$ (August) and the maximum is $77.22 \%$ (January). The study was conducted in 5 ecotypes (Figure 1). Sand flies were collected weekly from indoor (toilets and stables) and outdoor (around the houses, walls, rodent burrows, mountain and rock rifts), using sticky traps (castor oil coated white paper $20 \times 32 \mathrm{~cm}$ ) from the beginning (May) till 
the end (October) of the active season. Basic environmental conditions, including temperature and relative humidity, were recorded daily in each site with digital min-max thermometer/hygrometers. To determine hours of activity from sunset to sunrise, traps were installed and collected every 2 hours and were repeated 5 times in active season in one of the most populated collection sites. Traps were installed at 18:00 pm and run until 06:00 am the following morning. Then traps containing insects were collected and transported to the laboratory in Hamadan. For species identification, sand flies were mounted in Puri's medium and identified after 24 hours, using the keys of Mesghali [9] and Nadim and Javadian [10].

\subsection{Statistical Analysis}

The $\chi^{2}$ tests were applied to analyze the data. All analyses were performed by SPSS 16 software and Excel 2007. Levels of P value equaled to or less than 0.05 considered as significant.

\section{Results}

In this study the max registered temperature was $31^{\circ} \mathrm{C}$ and $\min 13^{\circ} \mathrm{C}$, respectively. The minimum mean monthly relative humidity was $38 \%$ and the maximum was $62 \%$. Three thousand three hundred and five sand flies (68.9\% males and 31.1\% females) including nine species were captured: P. sergenti (38\%), P. papatasi (36.6\%), P. major (10.1\%), P. kandelakii (6.7\%), P. wenyoni (5.0\%), P. caucasicus (1.2\%), P. halepensis (0.1\%), Sergentomyia dentata (1.2\%) and S. sintoni (1.1\%). No sand flies were caught until 25 May. P. sergenti was the most abundant species which contained $68.2 \%$ of all males and $31.8 \%$ of all females. Findings showed that the monthly activity of species began in late May and ended in early October with two peaks of activity in July and August, respectively (Figure 2).

The highest total frequencies, considering all the species captured over the one year, was observed in the summer (from 23 July to 30 August), with $81.8 \%$ of the specimens. P. sergenti almost was captured in all sampling, whereas P. halpensis was captured only in the warmest periods of activity season, exclusively in mountainous areas. The number of sand flies caught from indoor and outdoor places were respectively 755 (22.8\%) and 2550 (77.2\%). Regarding hourly activity, two very clear peaks of activity could be identified, one close to dusk (20:00 - 24:00 pm) and another at dawn (04:00 - 06:00 am), the second peak was not as high as the first peak. Activity of sand flies at dawn could be seen only in July and August.

\section{Discussion}

The present study resulted in the capture of 3,305 phlebotomines, representing 9 species. The activity of sand flies in Hamadan and vicinity started from May until October. Sand flies population showed two peaks in mid-July and late August. This is the first report of ecological aspects of sand flies in the Hamadan city and vicinity.

Ecological niche models are useful tools to recognize regional vector and measure epidemiological risk for infectious diseases such as leishmaniasis [11]. No sand flies were trapped until May in these areas because of climatic conditions. Warming triggered sand fly emergence in late May. As well, other factor such as wind speed can influence the presence and density of sand flies.

The highest density of species occurred during spring and summer. During the spring the variations of temperature and relative humidity were not so clearly perceptible but in the summer the temperature was high enough to support the development and activity of sand flies. Due to hot summer days and nocturnal activity of sand flies, the peak of species density occurs at dawn when the temperature and relative humidity are more favorable. So, the temperature and the humidity may influence the density of captured sand flies. Other study, carried out in similar environments to our surroundings, demonstrated that sand flies are usually found in greater numbers during warm and humid months [12]. In our study sand fly activity was more closely related to temperature condition than to any other climatic factor such as humidity. Due to occurrence of two generation of sand flies in Hamadan and presence of two activity pick in July and August the chance of receiving sand fly bite by human in these periods is more probable so, preventive measures should concentrated some time before these two peaks. The results of present study shows that almost all activity is restricted to period between 08:00 am and 12:00 pm and there is a sharp decrease in activity of sand flies after 12:00 pm which probably is related to relatively low temperature of area after this time. This finding is consistent with result of other study in northwest of Iran [13]. Since gravid females of $P$. sergenti were the first sand flies captured from late May in the beginning of active season, probably the hibernation of this species in Hamadan occurs as adult in the autumn and the winter. Also, sex ratio is similar to previous study in Hamadan [14]. It seems that sex ratio is related to type of sampling [15].

Some areas are distant from any peridomiciliary environment, where domestic animal shelters may act as an attraction factor and the difference between them may be attributed to the dense of vegetation, which protects them from the sun's rays, and probably, present a greater quan- 


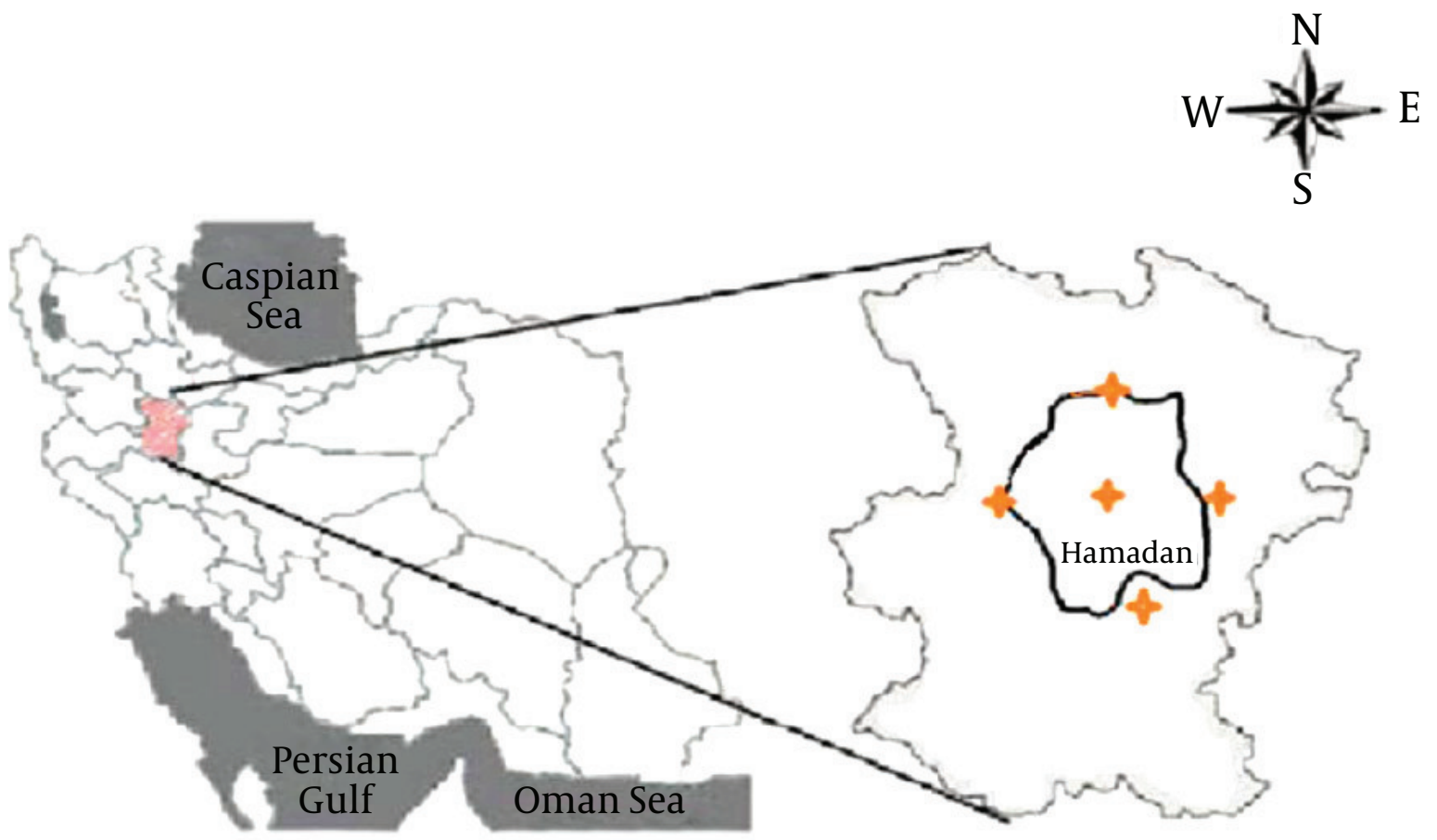

Figure 1. Map of Hamadan City, Shows the Location of the Study Areas

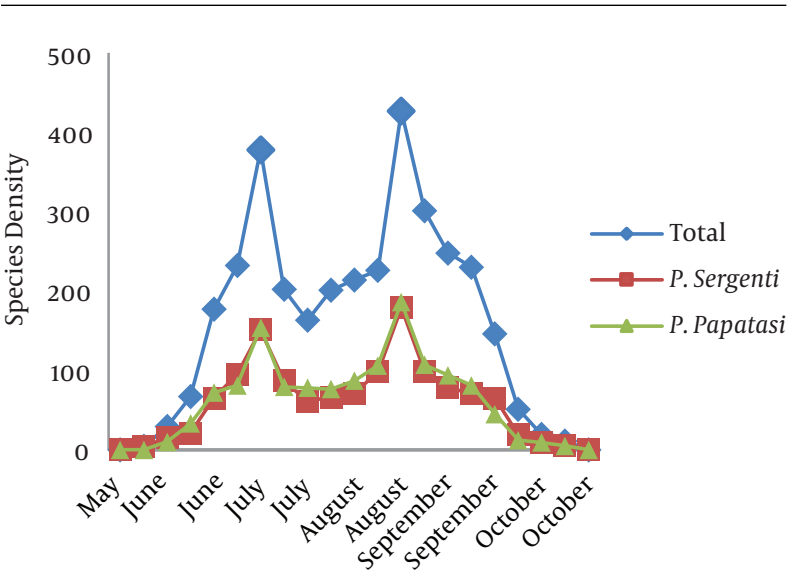

Figure 2. Seasonal Activity of Sand Flies From Indoor and Outdoor Resting Places, During the Activity Seasons Using Sticky Traps, Hamadan, West Iran, 2013

tity of organic matter that favours more numerous places for sand fly species. Also plant sugar sources provide the energy requirements. In addition, the relatively high numbers of species collected by sticky traps from plants and trees infested with aphids may reflect sugar feeding behavior because aphid honeydew was considered an important source of sugar for sand flies. But the low numbers or ab- sence of sand flies at some plants and trees in our study may indicate that these trees are not suitable sites for resting and breeding. The findings presented in this study have contributed to a better understanding of sand fly distribution within and around Hamadan, west of Iran. Since sand flies are vectors of cutaneous leishmaniasis or oriental sore (urban, rural) and Kala-Azar (mucocutaneous leishmaniasis has not been observed in Iran so far), these data will be of importance and may contribute to sand fly control program. In order to minimize the risk of transmission reduction of sand flies population is very important to eliminate these insects and prevention of disease.

\section{Acknowledgments}

We gratefully acknowledge Dr. Mohammad Ali Oshaghi, Dr. Amir Hossein Maghsood, Dr. Masoud Saidijam and Maryam Khedri members of Tehran University of Medical Sciences and Hamadan University of Medical Sciences for their valuable assistance. Saeed Porkeyhan and Dariush Bahrami helping us for collecting sand flies. 


\section{Footnotes}

Authors' Contribution: All authors contributed in design, working, statistical analysis and manuscript writing. Conflict of Interest: The authors declare no conflict of interest.

Funding/Support: This project received financial support from vice chancellor of research deputy of Hamadan University of Medical Sciences under the code 16/70/4/7514.

\section{References}

1. Aflatoonian MR, Sharifi I. Prevalence rate of cutaneous leishmaniasis in Bam district during 20 Years (1988 - 2007) [in Persian]. JKerman Univ Med Sci. 2010;17(4):297-306.

2. Ready PD. Biology of phlebotomine sand flies as vectors of disease agents. Annu Rev Entomol. 2013;58:227-50. doi: 10.1146/annurev-ento120811-153557. [PubMed: 23317043].

3. Jahanifard E, Navidpour S, Vazirianzadeh B. Study on phlebotominae on two big marshlands of Khozestan province, Iran. J Exp Zool India. 2009;12(2):407-8

4. Gonzalez C, Wang O, Strutz SE, Gonzalez-Salazar C, Sanchez-Cordero $\mathrm{V}$, Sarkar S. Climate change and risk of leishmaniasis in north america: predictions from ecological niche models of vector and reservoir species. PLoS Negl Trop Dis. 2010;4(1):585-8. doi: 10.1371/journal.pntd.0000585. [PubMed: 20098495].

5. Herwaldt BL. Leishmaniasis. Lancet. 1999;354(9185):1191-9. doi: 10.1016/S0140-6736(98)10178-2. [PubMed: 10513726].
6. Bagheri A, Sofizadeh A, Ghezel A, Ghanbari MR, Fadaei E, Yapang Gharavi M, et al. Ecological characteristics of sand flies in Golestan province, Iran (2011) [in Persian]. J Gorgan Univ Med Sci. 2013;15(4):849.

7. Rego FD, Shimabukuro PH, Quaresma PF, Coelho IR, Tonelli GB, Silva $\mathrm{KM}$, et al. Ecological aspects of the Phlebotominae fauna (Diptera: Psychodidae) in the Xakriaba Indigenous Reserve, Brazil. Parasit Vectors. 2014;7:220. doi: 10.1186/1756-3305-7-220. [PubMed: 24886717].

8. Sadlova J, Dvorak V, Seblova V, Warburg A, Votypka J, Volf P. Sergentomyia schwetzi is not a competent vector for Leishmania donovani and other Leishmania species pathogenic to humans. Parasit Vectors. 2013;6(1):186. doi: 10.1186/1756-3305-6-186. [PubMed: 23786805].

9. Mesghali A. Philebotominae (Diptera) of Iran, I. A Preliminary List, Description of Species and their Distributional Data. Acta Medica Iranica. 1961;4(1):20-73.

10. Nadim A, Javadian E. Key for species identification of sandflies (Phlebotominae; Diptera) of Iran. Iran J Publ Health. 1976;5(1):35-44.

11. Lainson R. The Neotropical Leishmania species: a brief historical review of their discovery, ecology and taxonomy. Revista Pan-Amazônica de Saúde. 2010;1(2):13-32. doi: 10.5123/s2176-62232010000200002.

12. Zahirnia A, Moradi A, Nourouzi N. Epidemiological survey of cutaneous Leishmaniasis in Hamadan province (2002-2007) [in Persian]. Sci J Hamadan Univ Med Sci. 2009;16(1):43-7.

13. Rassi Y, Javadian E, Nadim A, Zahraii A, Vatandoost H, Motazedian $\mathrm{H}$ et al. Phlebotpmus (Larroussius) kandelakii the Principal and Proven Vector of Visceral Leishmaniasis in North West of Iran. PakJ Biol Sci. 2005;8(12):1802-6. doi: 10.3923/pjbs.2005.1802.1806.

14. Nazari M, Zahirnia AH. Phlebotominae Sandflies Fauna (Diptera: Psychodidae) in Hamadan, Iran. Zahedan J Res Med Sci. 2012;14(8):18-20.

15. Mahdavifard H, Zahraie A, Behzistan R. Investigation on faunestic and seasonal activity of sand flies in Taibad county-side [in Persian]. Raze Behzistan. 2003;27:29-33. 